Anuario da Facultade de Dereito da Universidade da Coruña

Vol. 20 (2016), pp. 430-456

ISSNe: 2530-6324 || ISSN: 1138-039X

DOI: https://doi.org/10.17979/afdudc.2016.20.0.1952

\title{
CINCO PRIVILEGIOS MONÁSTICOS CONFIRMADOS POR ALFONSO IX DE LEÓN Y GALICIA EN TIERRAS DE LAXE (A CORUÑA) EL 25 Y EL 26 DE JULIO DE 1228
}

\author{
LUIS RODRÍGUEZ ENNES \\ Catedrático de Derecho Romano (Universidad de Vigo) \\ RR.AA de Jurisprudencia y Legislación y de la Historia
}

Fecha de recepción: 21.2.2016

Fecha de aceptación: 10.3.2016

Resumen: Alfonso IX, Rey de León y Galicia, no obstante el carácter itinerante de su corte, desarrolló una ingente actividad diplomática. Efectuó casi medio centenar de viajes por sus dominios galaicos y fue el único monarca hispánico que otorgó documentos en las aisladas tierras occidentales de su reino.

Abstract: Alfonso IX, King of Leon and Galicia, recovered - nevertheless the itinerant character of his Court - a great diplomatic activity. It realized almost half hundreds of trips for his Galician dominions and was the only Hispanic monarch who granted documents in the isolated lands of the Galician west.

Palabras clave: Alfonso IX, Galicia, documentos

Key words: Alfonso IX, Galician country, documents 
SUMARIO: I.- ALFONSO IX: NOTAS BIOGRÁFICAS. II.- UN REY CON UNA CORTE ITINERANTE. III.- EL MARCO HISTÓRICO-GEOGRÁFICO. IV.ANÁLISIS CRÍTICO DE LOS DIPLOMAS LAXENSES.

\section{ALFONSO IX: NOTAS BIOGRÁFICAS}

Muerto su padre, Fernando II, Alfonso IX llegó al trono leonés en 1188, con tan solo 17 años de edad no sin grandes dificultades ${ }^{1}$. En efecto, su madrastra, la reina doña Urraca López de Haro, consideraba que quien tenía mejor derecho a la corona era el infante Sancho, su hijo y no Alfonso, fruto del primer matrimonio de Fernando II que había sido anulado por consanguinidad entre los contrayentes, a la sazón, primos hermanos, lo que determinaba por ende, que Alfonso no pudiera ser considerado hijo legítimo ${ }^{2}$. El decreto de nulidad canónica es de 1175 al no conceder el pontífice las pertinentes dispensas y, por ello, la madre biológica de Alfonso, también llamada Urraca, hija de Alfonso Enríquez, primer rey lusitano, al dejar de ser reina se retiró a un monasterio de la Orden de San Juan de Jerusalén, dejando a su hijo en León. No obstante, Alfonso fue proclamado rey, sobre todo en razón a que así lo había reconocido su progenitor asociándolo como sucesor en sus propios documentos ${ }^{3}$, lo que originó un duro y largo enfrentamiento con su primo Alfonso VIII de Castilla ${ }^{4}$.

Así las cosas, muerto Fernando II en Benavente el 22 de enero de 1188, Alfonso fue proclamado su heredero, con el apoyo mayoritario del clero y la nobleza galaicoleonesa y la oposición de su primo el rey castellano Alfonso VIII. Ese mismo año,

\footnotetext{
${ }^{1}$ Los datos biográficos han sido entresacados de la monumental obra de GONZÁLEZ, J., Alfonso IX, 2 vols. (Madrid, 1944) que sigue constituyendo hoy en día el referente en la materia.

${ }^{2}$ Doña Urraca es la hija de Diego López de Haro, señor de Vizcaya y fundador de la villa de Bilbao y sobrina de Fernando Rodríguez de Castro, "el castellano"; con Fernando II — de quien había sido amante - tuvo dos hijos de los que sobrevivió el infante Sancho, nacido en 1184, para el que la propia reina, con apoyo de sus parientes, intentó reservar la herencia del trono de León, en detrimento de Alfonso, el hijo del primer matrimonio del monarca, siempre bajo el argumento de que este último había sido objeto de nulidad canónica.

${ }^{3}$ RECUERO ASTRAY, M., "Alfonso IX, rey de León y de Galicia (1188-1230), repoblador de A Coruña (1208)", en Alfonso IX de León y su época (A Coruña, 2008) p. 22.

${ }^{4}$ MARTÍN, J.L., "Alfonso IX y sus relaciones con Castilla", en Espacio, tiempo y forma, 7 (1994) p. 1131.
} 
primero de su reinado, tuvo lugar en León la convocatoria de una Curia Regia en la que figuran presentes los representantes de las ciudades y del pueblo como tercer estamento $^{5}$. De ahí que se haya afirmado sin ambages que esta curia leonesa constituyó las primeras cortes del reino, en el sentido democrático que hoy se les ha querido dar. Concretamente, Escudero señala que "estas Cortes leonesas constituyen las primeras asambleas de la Europa medieval a las que asisten ciudadanos elegidos ${ }^{6}$ ". La primacía cronológica de las Cortes de León y Castilla en Europa fue explicada y comentada por el historiador ruso Wladimiro Piskorski.

Alfonso IX, tratando de evitar la complicaciones con Castilla causadas por su madrastra acudió a las Cortes de Carrión donde besó la mano de su primo en acto de vasallaje $^{7}$, gesto que sus aduladores cortesanos le presentaron como humillante ${ }^{8}$ y del que se vengará buscando la alianza del monarca portugués contra Castilla casándose con Teresa de Portugal, hija del rey Sancho I y también prima hermana del monarca leonés 9 .

\footnotetext{
${ }^{5}$ Sobre esta sesión de la Curia Regia, vid.: FERNÁNDEZ CATÓN, J.M., La Curia Regia de León de 1188 y sus "decreta" y constitución (León, 1993). Como ya se ha indicado, estaban presentes en la asamblea de 1188 ciertos ciudadanos elegidos por distintas villas: In Dei nomine. Ego dominus Aldefonsus, Rex Legionis et Gallaeciae, cum celebrarem curiam apud Legionem, cum archiepiscopo et episcopis et magnatibus regni mei, et cum electis civibus ex singulis civitatibus, constitui et iuramento firmavi, quod omnibus de regno meo, tam clericis quam laicis, servarem mores bonos, quos a predecessoribus meis habent constitutos (Cfr. GONZÁLEZ, J., Alfonso IX, cit., II, p. 11).

${ }^{6}$ ESCUDERO, J.A., Curso de Historia del Derecho (Madrid, 1985) p 540-541, donde añade: "a lo largo del siglo XIII se institucionalizará la presencia ciudadana, consolidándose en consecuencia las Cortes". Para GARCÍA, C.H., "Alfonso IX de León et les cives du royaume (XII-XIII)", en CLCHM 27 (2004) p. 183 : "En 1188, Alphonse IX réunit une curia à León. L’historiographie a vu dans cette assemblée les premières cortes hispaniques en raison de la présence en leur sein du groupe de cives : les représentants des villes".

"En León y Castilla la capa social media consiguió acceso a las asambleas representativas, donde se debatían los intereses del Estado, considerablemente más pronto que en las otras monarquías europeas, gracias al temprano desenvolvimiento en aquellos reinos de la libertad política de los municipios, que nacieron y se afirmaron bajo la influencia de la necesidad de un ininterrumpido combate con los moros" [Cfr. PISKORSKI, W., Las Cortes de Castilla en el período de tránsito de la Edad Media a la Moderna, reedic. (Barcelona, 1977) p. 8].

${ }^{7}$ El estado de ánimo de Alfonso IX será definido años más tardes por el autor de Las Mocedades de Rodrigo cuando pone en boca del Cid los siguientes versos: "Allegó don Diego Laínez/ al rey besan la mano/ Quando esto vio Rodrigo/ non le quiso besar la mano.../ Porque vos la bessó mi padre/ soy mal amanzellado/". [ed. De DEYEMOND, A.D. Epic poetry and the clergy. Studies on the "Mocedades de Rodrigo" (Londres, 1969) p. 243].

${ }^{8}$ MARTIN, J.L., "Alfonso IX, cit. p. 14".

${ }^{9}$ GIL DE ZAMORA, J., explica así el matrimonio de Alfonso IX con Teresa de Portugal: "Este contubernio fue acordado por odio al rey de Castilla pues inficionado por sus cortesanos, se dolía Alfonso de haber recibido el cíngulo caballeresco de manos del rey de Castilla". [El texto latino de la biografía de Alfonso IX, procedente de la Biblioteca Nacional, códice 1727, fols. 71v.-73v., fue publicado en 1883 por FITA, "Biografía inédita de Alfonso IX, rey de León, por Gil de Zamora", en Boletín de la Real Academia de la Historia 13 (p. 291-295)].
} 
Alfonso IX tuvo con Teresa de Portugal, aparte del infante Fernando, a las Infantas doña Sancha y doña Dulce, que iban a estar vinculadas a la historia de A Coruña ${ }^{10}$. La unión del rey de León con Teresa de Portugal sería plenamente cuestionada desde la curia pontificia. Tras varios años de convivencia y el nacimiento de tres hijos, Roma decidió su separación atendiendo a la consanguinidad que unía a ambos monarcas ${ }^{11}$. Un concilio reunido en Salamanca, cuya cronología se ha fijado en los inicios de la última década del siglo XII ${ }^{12}$, presidido por el legado pontificio Rainiero, se dedicó al análisis del grado de consanguinidad del matrimonio de Alfonso IX y su esposa Teresa. El pontificado romano enviaba a su legado a León para, junto con los prelados del reino, declarar la invalidez del enlace dado que eran parientes en cuarto grado colateral. Roma buscó siempre la unidad de los príncipes cristianos contra los musulmanes, sin duda porque era consciente de la necesidad de la concordia para la victoria. La difícil coyuntura por la que atravesó Alfonso IX le situó al lado de los infieles. Esta política fronteriza, definida por C. de Ayala como escandalosa alianza leonesa con los califas almohades, produjo un fuerte desencuentro entre el monarca y la Iglesia ${ }^{13}$. Roma excomulgó a Alfonso IX y puso en entredicho al reino de León: Celestino III, anterior legado pontificio en Hispania ${ }^{14}$, lanzó contra él bulas condenatorias, negando la legitimidad que el monarca leonés intentaba aducir ${ }^{15}$.

Empero, Alfonso IX se da cuenta del peligro que entraña la alianza almohade y pacta una alianza con Castilla mediante su casamiento con doña Berenguela, hija mayor

\footnotetext{
${ }^{10}$ Sobre esta vinculación coruñesa de las infantas, vid., GONZÁLEZ GARCÉS, M., Alfonso IX y Crunia (A Coruña, 2008) p. 13 ss.

${ }^{11}$ CAVERO DOMÍNGUEZ, C., "Teresa de Portugal, reina de León” en Los Reyes de León (León, 1994).

${ }^{12}$ Antonio García lo sitúa entre los años 1191 y 1192, y añade: "El concilio, al que asistieron obispos de Castilla y León, declaró que debían separarse. Pero los obispos de León, Astorga, Zamora y Salamanca no asistieron al concilio, porque parece opinaban que el matrimonio era válido por no ser de derecho divino, sino de derecho humano civil y político, y que por lo mismo podían los mismos príncipes autodispensarse" [Cfr. GARCÍA GARCÍA, A., "Legislación de los Concilios y Sínodos del reino leonés" en El Reino de León en la Alta Edad Media, II, Ordenamiento Jurídico del reino (León, 1992) p. 96-97].

${ }^{13}$ Cfr. AYALA MARTíNEZ, C., "Las órdenes militares hispánicas en la Edad Media" (siglos XII-XV) (Madrid, 2003) p. 213.

14 Jacinto Boboni-Orsini recuerda especialmente su presencia como legado en España en la documentación leonesa relativa al monasterio de Sahagún, al que trata de ayudar recordando su anterior esplendor. Vid., DOMÍNGUEZ SÁNCHEZ, S., Documentos pontificios referentes a la diócesis de León. Siglos XI-XIII (León, 2003).

${ }^{15}$ CAVERO, G., "Alfonso IX y la Iglesia de su reino", en Alfonso IX y su época, cit., p. 89 ss.
} 
de Alfonso VIII y pariente en quinto grado colateral del leonés ${ }^{16}$. El matrimonio se realizó en $1197^{17}$. El matrimonio del Alfonso IX de León con doña Berenguela, violando el impedimento de consanguinidad, da lugar a cuatro cartas de Inocencio III dirigidas al monarca leonés sobre este asunto ${ }^{18}$. El 16 de abril de 1198 el Papa ordena a su legado Rainiero que declare nulo dicho matrimonio, recordándole de paso que haga observar la paz entre los reyes de España. El 25 de mayo del mismo año, el Papa manda al arzobispo de Compostela y obispos del Reino de León observar la sentencia de entredicho en el citado reino, por el matrimonio del Rey en contra de la normativa de la Iglesia. El 5 de junio de 1203 Inocencio III requiere al rey de Castilla que se disuelva la unión matrimonial entre su hija Berenguela y el rey Alfonso IX de León. Finalmente, el 19 de junio de 1204, Inocencio III manda al arzobispo de Santiago de Compostela y a los obispos de Zamora y Palencia que otorguen la absolución al rey leonés y levanten el entredicho sobre su reino. Con todo, cabe señalar que la disolución eclesiástica del matrimonio no fue acatada por los reyes. Nacieron de este enlace, Fernando - el futuro Fernando III- y otros tres hermanos. Uniones y separaciones, descendientes y legitimidades, generaron un enfrentamiento sucesorio, a la muerte de Alfonso IX, entre las hijas de Teresa de Portugal y el hijo de Berenguela de Castilla. La Iglesia tampoco fue pasiva ante la problemática sucesoria. Los obispos, por ejemplo, apoyaron a Fernando III de Castilla, hijo del segundo matrimonio en contra de la descendencia portuguesa habida en el primer matrimonio ${ }^{19}$.

Como nos transmite J. González las crónicas describen a Alfonso IX como un hombre fuerte, de aspecto notable y corpulento, con algunos rasgos que denotaban su progenie borgoñona como el hecho de ser rubio ${ }^{20}$. Lucas de Tuy lo presenta como el "hermoso, elocuente, clemente, fuerte físicamente y hábil en el uso de las armas y fiel católico", en un caso, y en otro recuerda que "en la guerra jamás fue vencido y siempre

\footnotetext{
${ }^{16}$ El tronco común partía de Alfonso VII, del que doña Berenguela era bisnieta — como nieta de Sancho III e hija de Alfonso VIII-y Alfonso IX nieto — como hijo de Fernando II-.

17 Doña Berenguela había estado desposada con Conrado de Suabia, hijo del emperador Federico Barbarroja. El matrimonio, no consumado al parecer por la aversión de la infanta castellana al príncipe germano, había sido disuelto en 1188.

${ }^{18}$ Las cartas papales están recogidas por D. MANSILLA, "La documentación pontificia hasta Inocencio III (965-1216)", en Monumenta Hispaniae Vaticana. Sección registros 1 (Roma, 1955).

${ }^{19}$ LINEHAN, P., La iglesia española y el papado en el siglo XIII (Salamanca, 1975) p. 107.

${ }^{20}$ GONZÁLEZ, J., Alfonso IX, cit. I, p. 201ss.
} 
salió vencedor cuantas veces combatió a cristianos o a musulmanes". Al margen de estos rasgos de su carácter - convenimos con Recuero Astray ${ }^{21}$ — que no es frecuente conocer en otros monarcas medievales que Alfonso IX fue un buen gobernante en el pleno desarrollo institucional y político de la Europa occidental. La fuerza que en su tiempo adquieren las Cortes leonesas así lo demuestra. El desarrollo cultural también tiene cabida entre los aspectos a resaltar dentro del reinado de Alfonso IX, no en vano fue el impulsor de la creación de la Universidad de Salamanca en 1218. Conquistó Extremadura $^{22}$ sentando las bases para la incorporación a Castilla de toda Andalucía, con la excepción de Granada, llevada a cabo por su hijo y heredero Fernando III. Murió en Sarria a finales de septiembre de 1230 y fue enterrado en la catedral de Santiago junto a su padre.

\section{II.- UN REY CON UNA CORTE ITINERANTE}

El escenario gallego, fue sin duda, el más practicado por Alfonso IX, especialmente en los años centrales de su reinado ${ }^{23}$. Como acertadamente señala GarcíaOsuna: Galicia era una región excéntrica del reino de León, en un realengo muy reducido y a veces discutido por su atrabiliaria nobleza, sobre todo en señores eclesiásticos, de los que los arzobispos compostelanos y la casa de Traba eran los más conspicuos $^{24}$. Cuando Alfonso $\mathrm{X}$ accede al trono no llegaba a la docena el número de individuos de la aristocracia leonesa que podían ser realmente considerados como magnates. Entre ellos, quizá el más distinguido de todos fuese el conde Gómez González de Traba, cuya familia había dominado la región de Trastámara desde principios del siglo X y, había ejercido el poder en otras muchas zonas de Galicia desde

\footnotetext{
${ }^{21}$ RECUERO ASTRAY, M., "Alfonso IX, rey de León” cit., p. 33.

${ }^{22}$ Acerca de la campaña extremeña, vid., PORRINAS GONZÁLEZ, D., "Alfonso IX y la desconocida conquista de Badajoz en 1230", en Sharia 71 (Badajoz, 2012) p. 10 ss.

${ }^{23}$ CAVERO DOMÍNGUEZ, G., "Alfonso IX de León y el iter de su corte (1188-1230)" en e-Spania. Revue interdisciplinaire d'études hispaniques médiévales et modernes 8 (2009) p. 1 ss., donde añade: "recordemos que allí se hallaba cuando murió Fernando II; en Galicia se armó caballero y en Galicia, en Compostela, acabó siendo sepultado. Es precisamente esta ciudad aquella en que más tiempo permaneció el monarca, allí donde acudió a la consagración de la catedral y allí donde celebró algunas curias: la que tuvo lugar en la primavera de 1211 allí se reunió. Y en el castillo de Sarria falleció a fines de septiembre de $1230 "$ ".

${ }^{24}$ GARCÍA-OSUNA Y RODRÍGUEZ, J.M., "Historia urbana de los reinos de León y Castilla en la Alta Edad Media" en Salamanca. Revista de Estudios 57 (2008) p. 361.
} 
entonces; durante el curso de una larga y prestigiosa carrera, el conde Gómez mantuvo por delegación de la corona las tenencias de Montenegro, Monterroso y Sarria, entre otras $^{25}$. El prestigio del conde era tal que durante el reinado de Alfonso IX su nombre aparecía a la cabeza de las listas de testigos que tradicionalmente se incluían en los documentos reales. Su hijo Rodrigo Gómez seguirá los pasos de su padre con una carrera distinguida en la corte de Alfonso IX y en la de sus sucesores Fernando III y Alfonso $\mathrm{X}^{26}$. El hecho de que Alfonso IX fuese capaz de permanecer en el trono durante cuarenta y dos años se debía principalmente a la estrecha y beneficiosa relación que supo mantener con la aristocracia de su reino.

Así las cosas, la corte de Alfonso IX, igual que la de otros muchos monarcas de la época, estaba en constante movimiento. Al no contar con una capital fija, el rey se veía obligado a desplazarse a lo largo de su reino para resolver los asuntos de gobierno, acompañado siempre por un considerable séquito de magnates laicos y eclesiásticos ${ }^{27}$. Ante todo, una amplia representación de los obispos del reino, sin duda los más implicados en su política: Bernardo, arzobispo de Compostela; Nuño, obispo de Astorga; Rodrigo, obispo de León; o los titulares de sedes más meridionales, como Ciudad Rodrigo, Coria y Salamanca. Siempre aparece el infante don Pedro ${ }^{28}$, mayordomo del $\operatorname{rey}^{29}$ y tenente de Limia, León, Toro, Zamora, Extremadura y

\footnotetext{
${ }^{25}$ BARTON, S., The aristocracy in twelfth-century León and Castille (Cambridge, 1997) p. 254-255. Otro mecanismo por el que los monarcas leoneses recompensaban a sus vasallos más importantes era a través de la concesión de tenencias. Para el rey, la ventaja de este sistema era doble. Primero, el monarca se aseguraba la lealtad de sus magnates al otorgarles estos feudos, ya que la rebelión por parte de estos podía conducir a la confiscación de los mismos. En segundo lugar, las tenencias conllevaban importantes deberes administrativos — entre ellos la recaudación de impuestos, la administración de justicia y el reclutamiento de tropas en tiempo de guerra- que el rey delegaba en sus nobles. Por lo que se refiere a los magnates, la posesión de una tenencia era a la vez símbolo de su posición social y de su poder, además de una fuente de riqueza, ya que el teniente tenía derecho a una parte de los beneficios fiscales y judiciales en la zona bajo su control [Cfr. Ibid. "Alfonso IX y la nobleza de León" en Alfonso IX y su época (A Coruña, 2002) p. 83].

${ }^{26}$ LÓPEZ SANGIL, J.L., La nobleza altomedieval gallega. La familia Froilaz-Traba (A Coruña, 2002) p. 171-182.

${ }^{27}$ Para detalles de sus itinerarios, vid: GONZÁLEZ, J., Alfonso IX, cit., II, p. 749-823.

${ }^{28}$ El infante don Pedro, de la casa real portuguesa, que se estableció en la corte leonesa en 1224 y ocupó el puesto de mayordomo hasta la muerte del rey seis años más tarde.

${ }^{29}$ El más importante cargo era el de mayordomo (maiordomus regis), que estaba a cargo de la organización de la casa real, incluyendo la custodia del tesoro. No se conoce con exactitud cuáles eran sus responsabilidades pero es probable que el cargo fuese predominantemente honorífico y que delegase sus deberes en un subordinado. El mayordomo era miembro permanente de la curia real y en ocasiones presidía algunos de los pleitos que ante ella se resolvían [Cfr. SALAZAR ACHA, J., La Casa del Rey de Castilla y León en la Edad Media (Madrid, 2000)]. Se conoce al menos la identidad de veintitres nobles
} 
Transierra. Están presentes con frecuencia Rodrigo Fernández de Valduerna, signifer ${ }^{30}$ del rey, tenente de Astorga, Mayorga, Oviedo y Benavente; otros nobles, como el ya citado Rodrigo Gómez y Fernando Gutiérrez, tenente perticam sancti Iacobi et Lemos ${ }^{31}$.

Para el otorgamiento de los diplomas, el monarca contaba con el titular de la cancillería, Pedro Pérez, maestrescuela de Ourense y canónigo compostelano; y varios scriptores: Sancho Fernandi, porcionario de Ourense; Martín Martínez, canónigo de Salamanca; y Alfonso, entre otros. Un pequeño grupo de magnates o ricohombres sobresalen entre la nobleza alfonsina. Este pequeño elenco habitualmente permanecía en la corte, casi de forma continua, al lado del rey, integrando una corte itinerante que se desplazaba a lo largo del año ${ }^{32}$. Entre ellos, el primero y más distinguido, como ya se tiene dicho, era el conde Gómez González de Traba, sin duda uno de los más poderosos magnates gallegos y defensor de los intereses de la corona desde la época en que Alfonso era infante. Siempre inicia la lista de nobles en los diplomas regios. También aparece Froila Ramírez, hasta su muerte a comienzos del siglo XIII, bien asentado en Astorga y El Bierzo; y Fernando Ponce, hijo de Ponce de Cabrera. Podríamos, por ello, entender que la administración se realizaba durante los viajes, o en las breves estancias regias, al igual que la celebración asamblearia.

\footnotetext{
que ostentaban el cargo de mayordomo durante el reinado de Alfonso IX, todos ellos de alto rango y posición (GONZÁLEZ, J., Alfonso IX, cit., I, p. 322-324).

${ }^{30}$ El segundo puesto de mayor relevancia tras el de mayordomo era el de alférez real o signifer como se le denomina en los documentos regios de la época. Era el encargado de liderar la milicia real y tenía la responsabilidad y honor de llevar la insignia regia en el campo de batalla [TORRES SEVILLAQUIÑONES DE LEÓN, M., Linajes nobiliarios de León y Castilla. Siglos IX-XII (León, 1990) p. 440451]. El cargo de alférez se asignaba normalmente a jóvenes miembros de las grandes familias nobles; por otra parte, el hermanastro del rey, el infante Sancho Fernández, ostentó el cargo entre 1213 y 1218.

31 Destaca entre el funcionariado especialmente el pertiguero, tenente peculiar del arzobispo compostelano a quien aseguraba su función señorial y la percepción de determinadas rentas de carácter feudal. Como recompensa de sus servicios cobraban para sí ciertos derechos. Ante los excesos de estos caballeros, el rey Alfonso IX otorgó un estatuto especial por el que limitaba sus percepciones a la recuperación de la "hogaza" cuya cuantía estipula [Cfr. LÓPEZ FERREIRO, A., Fueros municipales de Santiago y su tierra (Santiago, 1895-1896); VILLA-AMIL Y CASTRO, J., Los pertigueros de la Iglesia de Santiago (Madrid, 1873); más modernamente: GONZÁLEZ VÁZQUEZ, M., El arzobispo de Santiago: una instancia de poder en la Edad Media (1150-1400) (A Coruña, 1996) p. 245-252].

${ }^{32}$ BARTON, S., Alfonso IX y la nobleza, cit., p. 72-73.
} 
En sus desplazamientos, los monarcas medievales utilizaban frecuentemente, además de sus propios palacios ${ }^{33}$, otros albergues, especialmente monasterios, principalmente cuando estaban dotados de pequeños palacios o estancias áulicas; con todo, Alfonso IX data muy pocos de sus diplomas en monasterios, y casi siempre los que utiliza son gallegos ${ }^{34}$. Que el rey despacha los asuntos durante sus desplazamientos queda de manifiesto cuando utiliza expresiones como in camino, o cuando señala que determinados diplomas se fechan en lugares muy secundarios. Lo ordinario era dormir pocas noches en un mismo lugar y cabalgar mucho. Durante este continuo viaje iba el rey despachando sus asuntos, haciendo algunas paradas breves, en función de su actividad militar, repobladora y política.

\section{III.- EL MARCO HISTÓRICO-GEOGRÁFICO}

Si Galicia no ocupase el ángulo noroeste peninsular, su protagonismo en la forja de la nacionalidad española hubiera sido distinto. A la hora de la Reconquista no pudo tener un papel de primera protagonista. La decisión de Fernando I de dividir sus estados entre sus hijos, propició que Galicia se erigiese en un reino independiente, pero de vida efímera, pues en 1073 el rey García fue apresado por sus hermanos y sus dominios

\footnotetext{
${ }^{33}$ Entre los palacios reales figuraba a la cabeza el de S. Isidoro de León que se levantaba anejo al recinto eclesiástico, estructurado en distintas edificaciones que se asentaban desde la puerta Cauriense hasta la iglesia-panteón isidorianos, siguiendo el esquema palatino asturiano [Cfr. CAMPOS SÁNCHEZ BORDONA, D., Y PÉREZ GIL, J., El palacio real de León (León, 2006) p. 35-57]. Otros fueron los de Valdornia, Palacios de Valduerna, entre Astorga y La Bañeza, más cerca de la segunda donde en la Baja Edad Media se situaba la cabeza del señorío de los Bazán. En Laguna de Negrillas, para controlar la vía de la Plata, levantó Alfonso IX a comienzos del siglo XIII, un castillo que se integró en el proceso repoblador de la zona, castillo que aparece otorgado a la villa por el monarca en 1205 y que después pasaría a los Quiñones en época bajomedieval [Cfr. ÁLVAREZ ÁLVAREZ, C., "Castillos, Palacios y Torres de los Quiñones en la Baja Edad Media", en LANDERO QUESADA, M.A., (dir.) Castillos medievales del Reino de León (Madrid, 1998) p. 90-91]. Otro fue el antiguo palacio de Turcia en la vega del Órbigo, entre Carrizo y Benavides (GONZÁLEZ, J., Alfonso IX, cit., docs. 216, 326, 398). El palacio de Valbuena, en la comarca berciana, entregado posteriormente a su primera esposa, la ex reina Teresa de Portugal, para la fundación de un monasterio cisterciense [CAVERO DOMÍNGUEZ - GONZÁLEZ GARCÍA, M.A., El monasterio cisterciense de San Miguel de las Dueñas (León, 2000)]. En el castillo de Benavente, a comienzos de mayo de 1202, Alfonso IX celebró una curia plena en la que el monarca aparece acompañado por la reina Berenguela y el infante Fernando [HERNÁNDEZ VICENTE, S., "El concejo de Benavente y las tierras de su alfoz durante los siglos XII-XIV", en ARNAU BASTEIRO, E., (Ed.) Regnum, Corona y Cortes en Benavente (1202-2002). VIII Centenario de las Cortes de Benavente (Zamora, 2002) p. 141].

${ }^{34}$ GONZÁLEZ, J., Alfonso IX, cit. hace referencia expresa a los de Sobrado y Melón [Cfr. II, docs. 149 (Superado) y 546 (Melón)].
} 
reincorporados a León. El desplazamiento hacia el sur del eje político-económico del estado castellano leonés como consecuencia del avance de la Reconquista, que culminaría en la incorporación del valle del Guadalquivir por Fernando III el Santo (1217-1252) supuso la marginación de Galicia, cuya manifestación más evidente fue la pérdida de su voto en Cortes en 1348 — desde esta fecha hasta 1623 los procuradores de Zamora ostentarían también la representación del reino de Galicia ${ }^{35}$ - Y en la gran aventura colonial americana sus puertos atlánticos perdieron también una gran ocasión porque el camino a las Indias se canalizó a través de Cádiz y Sevilla. Económica y socialmente, Galicia siguió el desarrollo lento y marginal que la historia de la nación española le impuso. Su historia jurídica es el reflejo de esta situación ${ }^{36}$.

Más, si Galicia está ubicada en el finisterrae atlántico, las tierras de Laxe se hallan enclavadas en una de las costas más bravías de Europa ${ }^{37}$, lo que — sin duda — ha propiciado en mayor medida, si cabe, su multisecular marginación. Con todo, no deja de ser curioso que a lo largo de la dilatada historia de España, el único monarca que firmó documentos en tierras laxenses fue precisamente Alfonso IX. Hasta principios del siglo

\footnotetext{
${ }^{35}$ MOLINA MOLINA, A.L., "Prólogo" a EIROA, J.J., El retablo de la resurrección de Santa María de la Atalaya (Laxe, A Coruña) p. 11.

${ }^{36}$ Sobre esta situación, vid. RODRÍGUEZ ENNES, L., Aproximación a la Historia Jurídica de Galicia (Santiago de Compostela, 1999) passim.

${ }^{37}$ El nombre de Laxe según - MORALEJO LASO, A., Toponimia gallega y leonesa (Santiago de Compostela, 1977) p. 81, nt. 56 proviene de lágena — piedra plana— que así aparece en docs. de los siglos X y XI, probablemente de origen céltico. Según COROMINAS, Tópica, II, 220-221, port. lagem o lágea, gall. y cast. v. el texto V. también su Diccionario C.E.C.S.V. laja: "piedra naturalmente lisa, plana y de poco grueso", "piedra pizarrosa" tomado del port. lage o laja (también lagem, lagea). La villa de Laxe aparece nominada como "Lagea" (sic.) en portugués en su primera descripción pictórica debido al cartógrafo lusitano al servicio de Felipe IV, Pedro Texeira en su Atlas del rey Planeta, la descripción de España y de las costas y puertas de sus reinos (1634) p. 47, cito por la ed. anastática de Hondarribia (2002). Es un municipio de la provincia de A Coruña y diócesis de Santiago de Compostela, situado en el extremo occidental de la comarca de Bergantiños. Tiene una extensión de $33,62 \mathrm{~km}^{2}$ y una población de 3.579 habitantes que se agrupan en las parroquias de Serantes, Nande, Sarces, Traba, Soesto y Laxe. En el municipio de Laxe han sido catalogados cuatro recintos castreños en la parroquia de Serantes (Castro de Lourido y O Castelo), uno en la de Sarces (Petóns do Castelo, situado a 309 ms. de altitud) no conserva ningún resto arqueológico. El Castelo da Torre da Moa, el más reducido (40x25) cuenta con aún con dos lienzos de muro de sillares, que cierran un recinto cuadrado de época medieval, y en menor medida, castreña. (Cfr. RODRÍGUEZ CASAL, A., "Carta arqueológica del partido judicial de Carballo de Bergantiños (La Coruña)" Studia Arqueologica 34 (Santiago, 1975). Como ha señalado J.J. EIROA, "el territorio de la Costa da Morte situado en torno al núcleo de Laxe adquiere una importancia crucial a inicios del siglo XII, con la figura de Pedro Froilaz (1076-1128), conde de Traba, Miembro de un linaje decisivo en la Historia de Galicia, la Casa de Traba, ejerce como tutor de Alfonso Raimundez, futuro Alfonso VIII, desde 1105, por encargo de su padre Raimundo de Borgoña y su esposa Urraca. Encabezó aliándose con Diego Gelmírez, arzobispo de Compostela, la oposición a Alfonso I el Batallador, defendiendo los derechos del joven monarca a la corona, y fue desempeñando un papel cada vez más relevante en el espacio galaico-leonés (cfr. El retablo de la resurrección, cit., p. 34)".
} 
XIX Laxe se halló ligada, junto las tierras de Soneira a la jurisdicción de Vimianzo, dentro de la antigua provincia de Santiago de Compostela. En el siglo XIX, primero por el Decreto de Cortes del 27 de enero de 1822 y más tarde por el R.D. del 30 de noviembre de 1833, Galicia va a dividirse en las cuatro provincias actuales, quedando Laxe adscrita a la nueva provincia de $\mathrm{A}$ Coruña ${ }^{38}$. Un año más tarde, a raíz de la reforma administrativa del R.D. del 21 de abril de 1834 que proponía nuevas divisiones territoriales, Laxe, junto con las otras tierras dejaba de formar parte de la jurisdicción de Vimianzo, en tierras de Soneira, para pertenecer al partido judicial de Carballo, en tierra bergantiñana, lo que supuso su independencia de la jurisdicción señorial ${ }^{39}$.

Llegados a este punto, debemos preguntarnos cuándo y cómo realizó Alfonso IX este, su único viaje, a tierras de Laxe. Efectivamente, de las alrededor de cuarenta expediciones llevadas a cabo por el monarca en tierras gallegas, sólo podemos constatar como rigurosamente comprobada la efectuada a las aldeas laxenses de Soesto y Serantes los días 25 y 26 de junio de 1228. López Ferreiro nos dice que "consultando los documentos de aquella época vemos que Alfonso IX se hallaba el 25 de junio de 1228 en Soesto (Bergantiños) "40, pero no menciona concretamente el diploma que pueda confirmar la presencia del monarca en aquellas fechas. Con todo, pese a que Salvador Parga Pondal dice lo contrario ${ }^{41}$, sí figura en la magna obra de Julio González ${ }^{42}$, tantas veces citada. Además, puede fijarse el itinerario alfonsino siguiendo el rastro de los documentos expedidos por el monarca durante su recorrido. Alfonso IX partió desde Santiago $^{43}$, donde se encontraba el día 21 de junio procedente de Pontevedra ${ }^{44}$. Pasa por San Miguel de Treos, Tierra de Soneira, el $23^{45}$ y llega a la costa al día siguiente

\footnotetext{
${ }^{38}$ Sobre estos R.D. y, en general, sobre la reforma provincial de Javier de Burgos, vid.: RODRÍGUEZ ENNES, L., Las divisiones provinciales de Galicia: pasado, presente y futuro (Vigo, 2002).

${ }^{39}$ Acerca de la constitución del primer ayuntamiento de Laxe, cfr. BELLO, ROMERO C., Laxe, mirando al mar (A Coruña, 1999) p. 16.

${ }^{40}$ LÓPEZ FERREIRO, A., Historia de la Santa Iglesia Catedral, V (Santiago, 1902) p. 42.

41 "Tampoco lo hemos localizado nosotros" [Cfr. PARGA PONDAL, S., "Viaje de Alfonso IX por tierras de Bergantiños", en Boletín de la Real Academia Gallega 27 (1956) p. 384 ss.]

${ }^{42}$ GONZÁLEZ, J., Alfonso IX, cit., II, doc. 560, p. 653.

${ }^{43}$ Ibid. II, doc. 549, p., 699. Sobre esta estancia del rey en Pontevedra, vid.: RODRÍGUEZ FIGUEIREDO, M., “Alfonso IX en Pontevedra”, en Museo de Pontevedra XXIX (1975) p. 384 ss.

${ }^{44}$ Ibid., II, doc. 550, p. 650.

${ }^{45}$ Ibid., II, doc. 551, p. 651, transcribe un documento del 23 de junio otorgado apud Sanctum Michaelem de Tremes como acertadamente señala PARGA PONDAL, S., Comarca natural de Bergantiños (A Coruña, 2010) p. 349, nt. 230: "A identificación de Tremos con Treos préstase a algunha dificultade lingüística."
} 
instalándose en las Torres de Cereixo ${ }^{46}$. El viaje se efectuaba de modo rápido y por eso el 25 cruza la ría de Camariñas por las proximidades de Ponte do Porto y se detiene brevemente en Xaviña ${ }^{47}$. En la misma fecha, llega a Soesto ya en tierras laxenses y allí otorga el primero de los documentos objeto del presente estudio ${ }^{48}$.

La parroquia de S. Esteban de Soesto dista apenas tres kilómetros de la capital municipal. Su nombre proviene del prefijo $<$ sub $>$ y del sufijo <aestus $>$ detrás del flujo y reflujo del mar ${ }^{49}$. Topónimos que corrobora el más ilustre de los hijos de Soesto, el famoso cura liberal José Antonio Posse ${ }^{50}$, cuando alude a que nació en un lugarcillo que se llama así "por ser el más bajo e inmediato a las riberas del mar" está delimitada por el Océano Atlántico y Laxe. En el último censo tenía 232 habitantes en las entidades de Arrueiro, Casas Novas, Castrelo, Centeal y Soesto de Abaixo.

\footnotetext{
${ }^{46}$ En los núms. 552 a 557 hay consignados seis documentos datados en Seregiam los días 24 y 25 de junio, lugar que identificamos con la parroquia de Santiago de Cereixo, del municipio coruñés de Vimianzo.

${ }^{47}$ Docs. 558 y 559, págs. 658-659, datadas en Iavinam, el día 25 de junio. Santa María de Xaviña, parroquia del municipio de Camariñas, sita a la derecha de esa ría y próxima a Ponte do Porto y enfrente -ría de por medio- de Santiago de Cereixo.

${ }^{48}$ Se trata de un diploma mediante el cual confirma al monasterio de de Toxos Outos la donación de la iglesia de San Julián de Pereira, en Nemancos, hecha por él mismo en 15 de junio de 1219 (cfr. ibid., doc. 560).para un análisis pormenorizado de este instrumento nos remitimos al ap. III de este trabajo.

${ }^{49}$ Así en LEWIS-SHORT, A Latin Dictionary (Oxford, 1879) s. v. aestus se dice: "the undulating, heaving motion of the sea, the swell, surge " <fervet, aestu pelagus $>$ Cic. de orat. 3. 39.

${ }^{50}$ El 29 de noviembre de 1812, don Juan Antonio Posse, cura párroco de San Andrés de Rabanedo, pueblo cercano a León, dirigió la palabra a sus feligreses para ensalzar la nueva Constitución de España y recomendarles su acatamiento. Algunos días más tarde dio su discurso a publicar. Esta acción desembocó en una consecuencia inesperada: la confección, veinte años después, de uno de los documentos más curiosos de la literatura española. Vuelto los liberales por segunda vez al poder, con la accesión de Isabel II, los amigos de Posse le convencieron de que debía escribir sus memorias. Las persecuciones y calumnias que le había acarreado la publicación de su discurso sobre la Constitución le habían dado cierta fama en Castilla, no muy halagüeña por cierto, y parecía oportuno que presentase su apología al público en forma de autobiografía. Las memorias de Posse permanecieron desconocidas, fuera de un pequeño número de personas, hasta los años ochenta del siglo XIX, cuando su dueño se las mostró a D. Gumersindo de Azcárate, vecino de León, conocido a nivel nacional tanto por sus actividades universitarias como políticas. Por fin Azcárate consiguió que la revista La Lectura, de Madrid, dedicada a temas culturales, emprendiese la publicación del manuscrito de Posse que le habían regalado. Apareció en dieciocho de los números mensuales de esta revista, entre enero de 1916 y abril de 1918, con un total de 257 páginas bajo el título "Documentos de historia española moderna, memorias de Juan Antonio Posse". Al final de la última entrega, como en todas las anteriores, se prometió "continuará", pero no apareció más. Como ha señalado el gran hispanista estadounidense Richard Herr: "Aún truncada, la autobiografía de Juan Antonio Posse es de tal valor literario histórico que se debe dar a conocer de nuevo. Pocos de los españoles que vivieron antes del siglo XX se dedicaron a dar cuenta pública de sus vidas, y menos aun los que no eran ni escritores ni políticos, sino hombres sencillos del pueblo". [Memorias del cura liberal don Juan Antonio Posse con su discurso sobre la Constitución de 1812, ed. a cargo de Richard Herr (Madrid, 1984) p. 4].

${ }^{51}$ Historia biográfica, o historia de la vida y hechos de Don Juan Antonio Posse, escrita por él mismo hasta el año 1834, ed. Richard Herr (Madrid, 1984) p. 15.
} 
Población cuyo número debió permanecer inmutable a lo largo de todo el Antiguo Régimen $^{52}$.

En la impresionante historia diplomática de Alfonso IX solo constatamos un documento otorgado apud Soestum. Ello contrasta sin duda con la afirmación repetida de que el monarca tenía un palacio en Soesto donde residía largas temporadas. A nuestro juicio, no existe ninguna evidencia de ello ni documental ${ }^{53}$, ni arqueológica. Por otra parte, dada la prolija actividad de su cancillería, si dispusiese de un palacio en Soesto, su corpus diplomático constaría de muchos documentos signados en sede palatina y no de uno solo; por lo demás — según se infiere del desarrollo de la jornada de 25 de junio de 1228 - únicamente estuvo unas pocas horas en Soesto, ya que esa misma tarde se trasladó a la vecina parroquia de Serantes donde pernoctó. Así las cosas, no deja de sorprendernos la etimología oficial que le asigna al topónimo Soesto el propio Ayuntamiento de Laxe: "Do latín sub honesta (“debaixo dunha residencia de honor"). Actualmente non quedan vestixios desa construcción, pero las referencias históricas documentan que o rei Alfonso IX tería un pazo residencial no espazo que mais tarde vai a ser ocupado polo Pazo de Leis" ${ }^{\text {54 }}$. A modo de conclusión sobre este punto, me reitero en mi propuesta etimológica (soestus de sub-aestus) y rechazo por ahistórica y forzada la tesis palatina.

Al día siguiente -26 de julio- otorga cuatro documentos en la parroquia laxense de Santa María de Serantes ${ }^{55}$. Es una feligresía anexa a Santa María de Laxe (A Coruña), arciprestazgo de Soneira y diócesis de Santiago, delimitada por la ría de Corme e Laxe (N.), Sarces (S.), Canduas y Borneiro (E.) y Soesto (O.). Tiene 232 habitantes en las entidades de As Cabanas, Cabo de Area, Canle, Carrabete, Cenlle,

\footnotetext{
52 Así, en PASCUAL MADOZ, Diccionario Geográfico-Estadístico-Histórico de España y sus posesiones de Ultramar (Madrid, 1845), T. VI, Galicia, s. v. "Soesto", p. 1235 se contabilizan 224 almas.

${ }_{53}$ Como tendremos ocasión de señalar, Alfonso IX era especialmente cuidadoso a la hora de dejar constancia del lugar de otorgamiento del documento: in monasterio..., in palatio...

${ }^{54}$ Vid. por todos, VIDAL PÉREZ, X., Catalogación toponímica de Concello de Laxe (Laxe, s. f.) s. v. "Soesto": "Do latín sub honestum (debaixo dunha residencia de honor. Actualmente non quedan vestixios desa construcción pero as referencias históricas documentan que o rei Alfonso IX tiña un pazo residencial no espazo que máis tarde vai a ser ocupado polo Pazo de Leis".

${ }^{55} \mathrm{Se}$ trata de los docs. 560, 561 y 562 mediante los cuales confirma diversas donaciones al Monasterio de Melón (cfr. GONZÁLEZ, J., Alfonso IX, cit. II p. 660-661) y el doc. 563 (Ibid. p. 662) por el que efectúa la confirmación de varios derechos concedidos por el mismo rey al Monasterio de Melón en 14 de marzo de 1218. Todos ellos fueron otorgados apud Sarantes y serán analizados en el siguiente apartado.
} 
Lourido, Piñeiro, Romea, Salgueirón y Transfontáns ${ }^{56}$. Dista 2,5 kms. de la capital del municipio y se comunica por una carretera local $^{57}$. Para Moralejo Laso el topónimo "Serantes" es de origen prerromano ${ }^{58}$. En un contrafuerte del muro sur de la iglesia parroquial se encuentra un ara romana dedicada al dios indígena Cosus ${ }^{59}$. La falta de documentos nos dificulta la fijación del camino de vuelta y de los puntos en donde pernoctó las noches del 26 y del 27. Con todo, el 28, Alfonso IX se hallaba en A Coruña.

El primer documento fue otorgado en Soesto el 25 de junio de 1228 y en él se confirma al monasterio de Toxos Outos la donación de la iglesia de San Julián de Pereira en Nemancos, hecho por el mismo rey Alfonso IX en 15 de junio de $1219^{60}$. El

\footnotetext{
${ }^{56}$ En el ya citado Diccionario Geográfico de PASCUAL MADOZ, T. VI, s. v. "Serantes (Sta María de)", p. 1221 figura con 685 almas.

${ }^{57}$ Fuente: Gran Enciclopedia Gallega 28 (Gijón, 1974) s. v. "Serantes, Sta María de", p. 143.

${ }^{58}$ Cfr. MORALEJO LASO, A., Toponimia Gallega y Leonesa (Santiago de Compostela, 1970) p. 30, nt. 20, donde añade: "un sufijo o formación del plural o colectivo, primitiva en ara átono parece haber en topónimos como Bracara, hoy Braga, Láncara, Lózara, Tállara, Tábara, Támara; como también en apelativos como cáscara, gándara, sénara, de donde serna y senra (tierra de sembradura, y curiosa es así mismo la de los plurales, Arantes, Barbantes, Barrantes, Cesantes, Ourantes, Serantes, que también se encuentran fuera de Galicia y que parecen darse la mano con los étnicos y tribales a juzgar por una lápida de Tras-os-Montes de una mujer de la tribu Seurra y exs. C. (=centuria) Serante".

${ }^{59}$ La lápida, más bien una inscripción votiva de lectura compleja, tiene la siguiente leyenda: Coso/ Calaeu/nio P(ublius) S(ulpicius) E(x) V(oto) (una persona con nombre romano llamado Publio Sulpicio ofrece un exvoto al dios Caso Calaeunio). Cosus, en sus distintas acepciones era una deidad indígena, asociada a Marte. Esta inscripción ha sido analizada recientemente por el catedrático de Prehistoria de la Universidad de Murcia J. J. EIROA [cfr.: "Prehistoria y Antigüedad de la villa de Laxe (A Coruña)", en Varia Studia. Libro- homenaje al Prof. Dr. Luis Rodríguez Ennes, con ocasión de su septuagésimo aniversario (M. Barcia Lago y M. Fuenteseca Degeneffe (dirs.) (Pontevedra, 2015) p. 387 ss. ].

${ }^{60}$ Qvoniam cera res est tam fragilis quam putribilis, idcirco ego Adefonsus, Dei gratia rex Legionis et Gallecie, instrumentum donationis et concessionis siue confirmationis ecclesie Sancti Justi et ville de Pereyra que est in Nemancos, olim Deo et monasterio Sancti Justi a bone memorie rege domno Fernando patre meo concessum innouans et confirma $<n>s$ ad perpetuam rei memoriam et ut donatio et concessio siue confirmatio ipsa robur obtineat perpetue firmitatis et confirmationis sub bulla plúmbea de verbo ad uerbum iussi presentibus annotari, tenor autem ipsius instrumenti est iste: In Dei nomine. Notum sit ómnibus tam presentibus quam futuris quod ego Adefonsus, Dei gratia rex Legionis et Gallecie, do et hereditario iure concedo monasterio et fratribus Sancti Juliani cum villa de Perera cum omnibus directuris et pertinenciis suis sicut illam dedit et incartauit pater meus bone memorie rex domnus Fernandus domno Johanni Marino, et ipse Johannes Marinus postea per cartam dedit et concessit eidem monasterio supradicto de Togis Altis. Illam inquam ecclesiam Sancti Juliani cum villa de Perera que est in Nemancos do imperpetuum predicto monasterio iure hereditario habendam et possidendam concedo per términos suos et diuisiones antiquas sicut continetur in testamento quod fecit ipsi monasterio domnus Johannes Marinus. Hoc autem facio ego ob remedium anime mee et animarum parentum meorum. Siquis igitur tam de mea parte quam de extranea contra hoc meum factum uoluntarium ad irrumpendum uenire attemptauerit iram Dei omnipotentis et regiam indignationem incurrat et quantum inuaserit eidem monasterio in duplum persoluat et mille morabitinos in penam pro ausu temerario exsoluat. Carta semper in suo robore permanente. Facta carta in Romariz, $X V^{o}$ die junii, era $M^{a} C C^{a} L^{a}$ VII ${ }^{a}$. Petro IIII ${ }^{o}$ existente compostellano archiepiscopo. Johanne, ouetensis episcopo. Ordonio, lucensis episcopus.
} 
segundo, un día después - el 26- en la próxima parroquia de Serantes mediante el que confirma la donación de Vega de Francelos hecha por Fernando II al monasterio de Melón en marzo de $1166^{61}$. El tercero, de la misma data y lugar, por el cual confirma la

Laurencio, auriensis episcopo. Abbate aruensis Martinus, electo mindoniensis. Dommo Johanne Fernandi tenente Trastamar et Montem Rosum. Domno Martino Sancii tenente Limiam et Sarriam. Domno Fernando Fernandi tenente Cabreram et Beneuentum. Domno Gil Martinci tenente Taurum et Maioricam. Aluaro Ruderici tenente Mansellam et Uillam Fafilam. Petro Petri, archidiácono salamantino, tenente cancellariam. Magister Michaelis, domini regis notarius, scripsit et confirmat. Nulli igitur omnio hominum liceat hanc mee innouationis et confirmationis cartam infringere uel ei ausu temerario contraire, quod qui presumpserit iram Dei omnipotentis et regiam indignationem incurrat et quantum inuaserit duplo componat et pro ausutemerario regie parti in penam mille morabetinos exsoluat. Facta carta apud Soestum, XXV die junii, era $M^{a} C C^{a} L X^{a} V I^{a}$. Bernaldo existente compostellano archiepiscopo. Johanne, ouetensis episcopo. Roderico, legionensis episcopo. Nunone, astoricensis episcopo. Laurencio, auriensis episcopo. Michaele, lucensis episcopo. Stephano, tudensis episcopo. Martino, mindoniensis episcopo. Infante domno Petro, existente maiordomo domini regis tenente Legionem, Taurum, Zamoram, Extrematuram, Transserram et Limiam. Domno Roderico Fernandi, signifero domini regis, tenente Ouetum, Astoricam, Maioricam et Beneuentum. Domno Roderico Gomez tenente Montem Rosum, Montem Nigrum et Transtamar. Domno Fernando Guterriz tenente perticam Sancti Jacobi. Domno Petro Petri, mag<ist>roscolarum auriensis, canonico compostellano, existente cancellario domini regis. Martinus Fernandi, domini regis scriptor, scripsit. La donación a Toxosoutos es la única otorgada en este corpus documental a un cenobio benedictino. Este monasterio fue conocido con los nombres de Spinis altis, Togis altis y Togos outos (Tribunis altis), como pone de manifiesto SALVADO MARTÍNEZ, A., Tumbo de Toxosoutos. Siglos XII y XIII, doc. 6 (22-II-1146); doc. 14 (2XII-1154); doc. 56 (7-IV-1283) y doc. 21 (13-1-1169), respectivamente. En el documento de Soesto se le denomina Sancti Iusti, nomenclatura que se alterna con las anteriores a partir de la donación de Alfonso VII de 1138 de la Villam Gomariz y otras muchas propiedades a Pedro, Abbati Monasterii Sancti Iusti [Cfr. VAAMONDE LORES, C., "Santa Marina de Gomariz", en Boletín de la Comisión de Monumentos de Orense (en lo sucesivo BCMO), IV, 1910-1913, p. 8 ss.]. Fue levantado entre el 16 de octubre de 1132 - fecha de la donación de la ermita de San Justo para convertirla en cenobio - y el 5 de diciembre de 1135, cuando Alfonso VII acota los límites del monasterio [cfr. FREIRE CAMANIEL, J., El monacato gallego en la Alta Edad Media, II (A Coruña, 1998) p. 620]. En el año de 1475, el monasterio de Toxosoutos ingresó en el Císter [VALLE PÉREZ, J. C. La arquitectura cirterciense en Galicia I (A Coruña, 1982) p. 25, vid. también sobre esta cuestión, YAÑEZ NEIRA, D., Monasticon Cirterciense Gallego II (León, 2000) p. 193 ss.]. En consecuencia fue anexionado a Sobrado lo que conllevó la pérdida de su primitiva importancia e independencia, pues sus rentas pasaban a engrosar el patrimonio sobradense. En más de una ocasión se intentó cerrarlo, por la carencia de monjes, pero el general de la Orden se opuso. Durante el pontificado del papa Alejandro VI, que confirmó la anexión, tan solo había en San Xusto un prior y seis monjes. Continuó Toxosoutos como priorato hasta la Exclaustración [Cfr. DE SAA BRAVO, H., El Monacato en Galicia, I (La Coruña, 1972) p. 389-390].

${ }^{61}$ Quoniam... instrumentum donationis de Veiga que fuit de Francelos, que iacet contra Arnoiam, et de meditate Recie, olim a bone memorie patre meo rege domino Fernando Deo et monasterio Sancte Marie de Melon facte, innouans et confirmans (ut et domino ipsa)... hanc mee innouationis et confirmationis cartam (...) robore permanente (...) Adefonsus, domini regis scriptor, scripsi. (Lo demás como en el siguiente). Se trata de la primera de las cuatro donaciones alfonsinas al monasterio cirterciense de Melón. Nada sabemos con seguridad de su origen. Antes de 1158 no tenemos vestigios documentales del cenobio. Muchos autores, entre ellos el P. Yepes, dan la fecha de 1142 como fundación del monasterio sobre la base de un privilegio otorgado por Alfonso VII al abad Giraldo, monje venido de Claraval para implantar la reforma cirterciense en Melón. Otorgó el rey en este privilegio al monasterio, el coto de Melón, que comprendía los lugares de Melón, Quines y Vilar de Condes, limitando sus términos y exonerando a sus monjes de toda jurisdicción real y episcopal [YEPES, Fray A. de, Crónica General de la Orden de San Benito, III (1609-1621), p. 123-125, cito por la edic. de Fray Justo Pérez de Urbel (Madrid, 1959)]. Con todo, habida cuenta de que tal privilegio no se conserva, no constituye una base sólida en la que apoyarse [Cfr. LOSADA MELÉNDEZ, J.- SOTOLAMAS, M. T.- GONZÁLEZ, M. A., "Santa María de Melón", en Monasticon cirterciense, cit., I, p. 138; en este sentido es convincente la 
donación de la iglesia de Santa María de Daravo, hecha por Alfonso IX al monasterio de Melón en 15 de abril de $1201^{62}$. El cuarto, en la idéntica fecha y localidad, confirma al Monasterio de Melón y traslada la donación de Merz hecha por el mismo monarca en 5 de febrero de $1193^{63}$. Y el quinto y último, también del 26 de junio de 1228 en Serantes confirma el privilegio de varios derechos, concedido por Alfonso IX al monasterio de Melón en 14 de marzo de $1218^{64}$.

Lo que llama más la atención de los documentos aportados es que todos ellos son confirmación de donaciones otorgadas previamente bien por el propio Alfonso o, en un supuesto, por su progenitor Fernando II, al monasterio cisterciense de Melón —en cuatro de los instrumentos- ${ }^{65} \mathrm{y}$ al benedictino de Toxos Outos, en uno solo. La razón

argumentación de VALLE PÉREZ, J. C., La arquitectura cirterciense, cit., I, p. 207]. La primera mención documental del monasterio de Melón sería la donación que el 12 de mayo de 1158, hace a la ecclesie Sancte Marie de Melone la condesa Fruela Fernández (FREIRE CAMANIEL, J., El Monacato Gallego, cit., II, p. 771). El monasterio se incorporó a la Congregación reformada de Castilla en el año 1506. La unión castellana supuso para Melón lo mismo que para otros monasterios de Galicia, la pérdida de su antonimia administrativa, saliendo para tierras castellanas gran parte de las rentas que aquí cobraba. Durante las guerras de la Independencia y Carlista sufrió el acoso de los invasores. Después la exclaustración y la desamortización completaron la obra, dispersando su archivo, biblioteca, ornamentos y vendiéndose sus bienes con tales ventas (Cfr. DE SÁA BRAVO, H., El monacato en Galicia, cit., II, p. 159-160). El documento está publicado por J. GONZÁLEZ, Alfonso IX, cit., II, nº 561.

${ }^{62}$ Quoniam (...) instrumentum donationis medietatis ecclesie Sancte Marie de Arauo necnon integri casalis de Santelo olim Deo et monasterio Sancte Marie de Melon sub sigillo cereo a me concessum, innouans ad perpetuam rei memoriam et ut donatio ipsa robur obtineat perpetue firmitatis. Nulli (...) hanc mee donationis et confirmationis cartam (...) exsolvat. Facta carta apud Serantes, XXVI, die junii, era MCCLXVI. Publicado por J. GONZÁLEZ, Alfonso IX, cit., II, $\mathrm{n}^{\circ} 562$.

${ }^{63}$ Quoniam (...) instrumentum donationis tocius regalengi de Merz, olim Deo et monasterio Sancte Marie de Melon facte, innovans ad perp. (...) et ut donatio ipsa. Nulli igitur (...) hanc mee innovationis cartam (...) exsolvat. Facta carta apud Serantes XXVI die Junii era MCCLXVI. Publicado por J. GONZÁLEZ, Alfonso IX, cit., II, $\mathrm{n}^{\circ} 563$.

${ }^{64}$ (...) instrumentum concessionis et confirmationis decime partis, portatici, calumpniarum et aliarum directurarum quod ad ius legale pertinent vel pertinere debent in burgo de Melon olim Deo et monasterio de Melon sub sigillo cereo a me concessum, innovans (...) ut concersio et confirmatio ipsa robur (...) hanc cartam mee confirmationis infringere. Publicado por J. GONZÁLEZ, Alfonso IX, cit., II, $\mathrm{n}^{\circ} 564$. Este documento fue objeto de falsificación por Pedro de Sotomayor con el objeto de apoderarse de tierras y pertenencias monásticas [Para esta cuestión, vid.: ARRIBAS ARRANZ, F., "Una importante falsificación de documentos a principios del siglo XVI", en Boletín del Museo Arqueológico Provincial de Orense, IV, p. 59-125]. El controvertido documento había sido dado al procesado por el merino de Melón.

${ }^{65}$ Se trata de mercedes regias dirigidas a instituciones eclesiásticas por los monarcas de la Edad Media leonesa: las motivaciones piadosas son una realidad esencial en la configuración de las instituciones feudales. Monasterios y sedes diocesanas son beneficiarios preferentes de tales concesiones, si bien cumple constatar - que, como se infiere claramente de los documentos objeto de nuestro análisis, la orden cirterciense, en este caso Melón, sale mucho mejor beneficiada que la benedictina, sin duda debido a la querencia de los ancestros borgoñones de Fernando II y Alfonso IX por los monjes bernardos. Es tópica la liberalidad de Fernando II con los monasterios del Cister de su reino. [La ponía de relieve el mismo GONZÁlEZ, J., Regesta de Fernando II (Madrid, 1943), passim, e insisten en ella trabajos 
de ser de tales confirmaciones nos es expuesta palatinamente en la arenga inicial: Quoniam cera res est tam fragilis quam putribilis. El monarca alude, pues, a que la cera del sello regio está deteriorada, de ahí la necesidad de emitir un nuevo instrumento confirmatorio. Empero, los otorgantes de los diplomas leoneses en la mayor parte de los casos no aluden a las motivaciones o móviles que les impulsan a realizar el negocio jurídico que se expresa en cada diploma. Esto es corriente, por otra parte, en los documentos de cualquier otra área geográfica. Pero es usual también que otras veces expongan las motivaciones de carácter profano y de tipo religioso que les mueven a realizar el acto jurídico que en el correspondiente diploma se realiza ${ }^{66}$. Aquí aparecen ambos, pues el monarca alude a que la cera del sello regio está deteriorado, de ahí la necesidad de emitir un nuevo instrumento confirmativo. Siempre que el documento tiene arenga comienza con Idcirco — como en estos casos-o sus equivalentes: Hinc est quod, ea propter, eo prospectu ${ }^{67}$. Los diplomas se encabezan con una invocación religiosa: In Dei nomine. Cabe preguntarse cuál es el origen y contenido real de esta invocación. Su origen se remonta mucho más lejos en el tiempo y el espacio que los diplomas leoneses o cualesquiera otros diplomas medievales europeos. Con una invocación del nombre de Dios o de Cristo comienzan numerosas obras de la patrística tardía y de la Alta Edad Media, como puede comprobarse por los incipiarios ${ }^{68}$. Así se encabeza también el texto de numerosos concilios y otras obras más lejanas de la literatura eclesiástica, como la segunda edición del Codex Iustinianus, cuyas primeras palabras del primer libro comienzan: In nomine Domini nostri Iesu Christi Codicis domini nostri Iustiniani sacratissimi principis repetitae praelectionis liber primus ${ }^{69}$. También aparece esta invocación al principio del Digesto, aunque puede tratarse de una

posteriores, principalmente los de ÁLVAREZ PALENZUELA, V. A., "Iglesia y monarquía en el reinado de Fernando II", en Santo Martino de León. Ponencias del I Congreso Internacional sobre Santo Martino en el VII Centenario de su obra literaria (1185-1985), (León, 1987) p. 135-152 o el posterior de RECUERO ASTRAY, M., "Relaciones entre la monarquía y la Iglesia de León durante la Alta Edad Media", en El reino de León en la Alta Edad Media, VII (León, 1995) p. 71-148]. De su sucesor, es también conocido el freno puesto a la anterior generosidad y sobre todo la instrumentalización de la misma en proyectos mucho mejor definidos de articulación del poder real [En el trabajo anteriormente citado, RECUERO, p. 13 define al reinado de Alfonso IX en cuanto a sus relaciones con el estamento eclesiástico como "la culminación de todo el proceso de alianza y colaboración para la propia construcción del reino de León"].

${ }^{66}$ GARCÍA Y GARCÍA, A., Iglesia, Sociedad y Derecho 3 (Salamanca, 2000) p. 385.

${ }^{67}$ GONZÁleZ, J., Alfonso IX, cit., II, p. 536.

${ }^{68}$ VATASSO, M., Initia patrum latinorum aliorumque scriptorum eccleriasticorum latinorum ex Migne Patrologia et ex compluribus aliis libris (Ciudad del Vaticano, 1906) (Studi e Testi 16) p. 543-545.

${ }^{69}$ KRÜGER, P., Corpus Iuris Civilis, II: Codex Iustinianus (Berlín, 1887-1959) p. 5. 
interpolación posterior, dado que no figura en el códice florentino de la littera pisana como ya advirtió en su día Elio Antonio de Nebrija ${ }^{70}$. El Fuero Real en el siglo XII, comienza con estas palabras: "En el nombre de Dios. Amén"71.

En todo caso, el rey habla en primera persona singular Ego Adefonsus Dei gratia rex Legionis et Gallaeciae, la intitulación comprendiendo ambos reinos fue empleada por Alfonso IX durante su reinado, si bien, a partir de 1230, su hijo Fernando III va a sustituirla por la de rex Legionis et Castellae, continuada por todos sus sucesores. Seguidamente, tras aludir a la anterior donación, el monarca galaico leonés explica que su confirmación va a hacerse ipsa robur obtineat perpetue firmitatis et comfirmationis sub bulla plumbea, para erradicar los inconvenientes desviados del empleo previo de un material tam fragilis quam putrilibus como es la cera. La notificación — nunca falta en este tipo de documentos - aquí no se dirige a una dirección concreta sino a todos los presentes y futuros (tam presentibus quam futurus).

La disposición se hace sin perífrasis, de un modo directo: sujeto en primera persona del singular: Ego Adefonsus Dei gratia rex Legionis et Gallaeciae, do et hereditario iure condendo; sigue en dativo la identificación del beneficiario: monasterio et fratribus Sancti Iusti de Togis Altis et vobis domino Johanni eiusdem monasterii abbati. La determinación local del objeto es breve y escueta: ecclesiam Sancti Iuliani cum villa de Pereira cum omnibus directores et pertenenciis suis (en el documento de Soesto) y, en los cuatro de Serantes, respectivamente: Veiga que fuit de Franzelos, que iacet contra Arnoiam, et de meditate Recie. En el segundo: fuit medietatis ecclesie Sancte Marie de Arauo necnon integri casalis de Sautelo. En el tercero: totius realengi de Mera y en el cuarto: decimi partis petiti, portatici, calumpniarum et aliarum directurarum quod ad ius regale pertinere. De las cuatro donaciones otorgadas en Serantes es beneficiario el monasterio cirterciense de Melón. El motivo de la dispositio va inmediatamente detrás. Ordinariamente es por remedio de su alma y de las de sus

\footnotetext{
${ }^{70}$ AELII ANTONII NEBRIGENSIS, Annotationes in Libro Pandectarum (Ael. Antonii Nebrissensis, Gramm. Opera 2). Introducción y ed. crítica por A. García, trad. por Arantxa Domingo Maldonado (Salamanca, 1996) p. 65.

${ }^{71}$ Cfr. Los Códigos españoles concordados y anotados, 1. (Madrid, 1847, LXXVII) p. 7.
} 
antecesores, tal acontece en los documentos de Laxe: Hoc autem facio ego ob remedium anime mee et animarum parentum meorum.

Anteriormente nos hemos ocupado de las invocaciones iniciales que —al igual que en los diplomas objeto de nuestro estudio - se encuentran en la mayoría de los instrumentos leoneses medievales. Pasaremos ahora al análisis de las fórmulas finales en las que se contiene una sanción contra los que infrinjan lo establecido en el documento correspondiente. Como norma general puede establecerse que la sanción en esta época es completa, constando siempre de penas materiales y espirituales. Así se consigna en los diplomas laxenses que - al igual que muchos otros provenientes de la cancillería alfonsina - empiezan la sanción con la hipotética: Siquis igutur tam de mea parte quam de estranea contra hoc meum factum voluntarium ad irrumpendum venire adtemptavenit iram Dei omnipotentis et regiam indignationem incurrat et quantum invaserit eidem monasterio in duplum persoluat et mille morabitinos ${ }^{72}$ in penam pro ausu temerario exsolvat. El beneficio resultante de la multa se reserva para el rey ya que se establece como pena por el atrevimiento de quebrantar un acto real et pro ausu temerario. La pena normal establecida en composición de los daños hechos consiste en satisfacer el doble: in duplum persolvat y su beneficiario es el monasterio. Cuestión aparte es la referencia a la regiam indignationem. Ira e indignatio regis aparecen en la Biblia como un paralelo de la ira e indignación de Dios, cuyo lugar en la tierra ocupaban en cierto modo los monarcas según la teoría política medieval. En este sentido, se alude en algunos pasajes bíblicos a la ira e indignación regias: indignatio regis nuntii mortis sapientis placabit ${ }^{73}$, regis ira quierit ${ }^{74}$, sicut frenitus leonis ita et regis ira $^{75}$, etc. En los derechos seculares se ha desarrollado la institución llamada "ira regia”, que reviste diferentes significados en distintos tiempos y lugares, que van desde la imprecación hasta contener penas concretas. Para Castilla y León este argumento ha

\footnotetext{
${ }^{72}$ Para A. LÓPEZ FERREIRO, Historia, cit., V, p. 58, nt. 1: “el morabitino venía a valer la séptima parte de una onza de oro". Según el DRAE se trata de "una antigua moneda española, maravedí. Moneda almorávide, de plata, muy pequeña".

${ }^{73}$ Prov. $16,14$.

${ }^{74}$ Esth. 7, 10.

${ }^{75}$ Prov. 19, 12.
} 
sido objeto de un amplio estudio de Hilda Grassoni ${ }^{76}$. Al final aparece una confirmación de la sanción temporal, a la que se le añade una de tipo espiritual: la ira Dei (quod qui presumpserit iram Dei omnipotentis). Las sanciones espirituales auguran castigos divinos para esta vida, para la otra o para las dos. La ira Dei es un antropoformismo por el que se supone que Dios adopta una actitud airada e indignada cuando los humanos le ofenden y en este sentido aparece en infinidad de textos bíblicos ${ }^{77}$. Contra lo que a primera vista pudiera parecer, estas imprecaciones de los diplomas alfonsinos y otras similares carecen de todo valor jurídico debido a que no están formuladas por ninguna autoridad eclesiástica competente. Son generalmente de imposible realización ya que se trata de castigos divinos que sólo Dios podría ejecutar, y Dios nunca ha prometido hacerlo ni los hombres son competentes para dictar castigos que Dios debería irrogar. En algún caso como el de la ira o indignación regias, sí pueden tener efectos jurídicos si la ley real así lo dicta. Esto último acontece con temas temporales, no con las espirituales, ya que hay casos en que el rey amenaza en algún diploma con la excomunión, cosa que él no puede aplicar en modo alguno. Por ello, todas estas fórmulas que conminan castigos divinos, sólo tienen un valor puramente testimonial o apelación a la conciencia cristiana de los posibles infractores, apelación que no se relaciona para nada con el mundo jurídico ${ }^{78}$.

Los documentos aparecen datados el 25 de julio de 1228 -el de Soesto- y el 26 los de Serantes-. El dato de expresar el lugar en que fue otorgado el diploma no aparece de modo regular hasta los promedios del reinado de Alfonso VII; con anterioridad es rara su presencia. Desde 1135 en adelante es excepcional su omisión ${ }^{79}$. Por lo que hace a la expresión del día del mes, este dato es de lo más constante a partir de 1197 y demuestran que en 1228 ya se había generalizado el sistema directo o actual en lugar del romano o de calendas, nonas, e idus; la adopción de esta novedad parece haberse

\footnotetext{
${ }^{76}$ GRASSONI, H., "La ira regia en León y Castilla", en Cuadernos de Historia de España, XLI-XLII (1965) p. 5-135, reeditado en el libro de la misma autora Miscelánea de estudios sobre instituciones castellano-leonesas (Bilbao, 1978) p. 1-431.

${ }^{77}$ DE RAZE, LAUCHAND, FLANDRIN, Concordatium SS. Scripturae Manuale (Barcelona, 1958) s. v. "ira e indignatio con otras concordancias bíblicas".

${ }^{78}$ GARCÍA GARCÍA, A., Iglesia, cit., 3, p. 471.

${ }^{79}$ MILLARES CARLO, A., "La cancillería real en León y Castilla hasta fines del reinado de Fernando III", en AHDE 3 (1926) p. 227.
} 
debido a los notarios Petrus y Dominicus hacia los alrededores de $1197^{80}$. En los documentos laxenses, el año viene expresado por la era española: "era MCCLXVI = anno domini MCCXXVIII. Los instrumentos datados por el año de la Encarnación son verdaderamente excepcionales. Sus confirmantes están señalados guardando rigurosamente el orden fundamental de columna primera para los obispos (Bernaldo, arzobispo de Santiago, Juan, obispo de Oviedo; Rodrigo de León; Nuño, de Astorga; Lorenzo, de Oviedo; Miguel, de Lugo, Esteban, de Tuy; Martín, de Mondoñedo) y la segunda para los nobles seglares (El infante Don Pedro existente maiordomo domini regis tenente Legionem, Taurum, Zamoram, Extrematuram, Transserram et Limiam. Rodrigo Fernández signifero domini regis, tenente Oaetum, Astoricam, Maioricam et Beneventum. Rodrigo Gómez tenente Montem Rosum, Montem Nigrum et Trastamar ${ }^{81}$. Fernando Gutiérrez tenente perticam Sancti Jacobi. El listado de confirmantes se efectuaba según era costumbre en el reinado anterior pero con una novedad cual es la de no aparecer el confirmat de modo explícito en dichas columnas, limitándose éstas a ser listas de nombres y cargos con régimen especial, toda vez que hallamos una construcción gramatical distinta por falta de dicho verbo; los nombres se construyen en el ablativo absoluto. Esa costumbre, generalizada en todo el reinado, no se introdujo desde el primer momento. Hasta el 30-IV-1991 se usó la forma antigua: Petrus Compostellanus archiepiscopus conf., Comes Gomez tenens Transtamaram et Limiam conf. Pero desde el mes de junio de dicho año, inclusive, en adelante la forma es la nueva de que hablamos: Manrico Legionensi episcopo, Comite Ferdinando ${ }^{82}$. El orden

\footnotetext{
${ }^{80}$ El hecho fue ya observado por ALFONSO NÚÑEZ DE CASTRO en su Crónica de los Señores Reyes de Castilla Don Sancho el Deseado, Don Alonso el Octavo y Don Enrique el Primero (Madrid, 1665) p. 200: "En las escrituras del año pasado (1199) y de este (1200) —escribe- parece que él dexó el Rey D. Alonso las Kalendas, Idus y Nonas de la cuenta de los Romanos y puso los días del mes, como ahora contamos en Castilla y esto ha reparado después que faltó el Maestro Micha o Miguel y entró Pedro por notario, la alternancia de ambos sistemas se da en diplomas de Alfonso IX".

${ }^{81}$ Suena el nombre de Rodrigo Gómez, nieto del famoso conde D. Pedro Fernández de Traba, sin interrupción, desde los primeros años del siglo XIII hasta faltar pocos para llegar a su último decenio, y figura en memorables empresas y es mencionado en nada escaso número de documentos bajo múltiples y muy diversos conceptos: tan pronto designa valeroso guerrero, magnánimo otorgante de fueros municipales, prudente árbitro de enconados litigios, piadoso favorecedor de corporaciones religiosas, espléndido donante a iglesias y monasterios o devoto expedicionario a Tierra Santa; como ruin facineroso, azote de villanos y de eclesiásticos, detentador de propiedades eclesiásticas, robador de hombres, ladrón de cabalgaduras y ganados, exactor de impuestos indebidos, simoníaco codicioso, o desleal hasta la felonía y causante de tropelías y males sin cuento del género más bajo y repugnante [Cfr. VILLA-AMIL Y CASTRO, J., "Rodrigo Gómez: cuadro histórico de las costumbres de la nobleza gallega en el siglo XII", en Grial 33 (1971) p. 273 ss.]

${ }^{82}$ GONZÁLEZ, J., Alfonso IX, cit., II, p. 545.
} 
de personas dentro de las columnas suele establecerse conforme a gradación jerárquica, al menos por lo que al primer lugar corresponde: Bernardo existente compostellano episcopo. Infante domino Petro.

La redacción de los documentos fue encomendada a un funcionario perteneciente por lo común al estamento eclesiástico como se deduce claramente del contexto: Domino Petro Petri ${ }^{83}$ magistroscolarum auriensis, canonico compostellano, existente cancellario domini regis. El notario aparece al final: Martinus Fernandi, domini regis scriptor, scripsit.

Como se ha indicado repetidas veces, los documentos están redactados en latín y fueron otorgados dos años antes de fallecer Alfonso IX cuya cancillería, dependiente del arzobispo compostelano, había emitido todos sus diplomas exclusivamente en lengua latina. La única excepción aparente la constituye el Foral del Burgo de Caldelas, privilegio rodado escrito originalmente en latín y otorgado por Alfonso IX en Allariz en el mismo año de 1228, como actualización del fuero latino concedido por Fernando II en 1172. Del foral se conserva una copia coetánea en gallego, de hacía 1250, que parece haber sido elaborada en el propio concejo de Caldelas ${ }^{84}$. Empero, como ha demostrado Inés Fernández-Ordoñez en los años previos a la unión con León, la cancillería castellana, vinculada a la curia arzobispal de Toledo, venía redactando esporádicamente, en cambio, documentos en castellano. Con todo, tras la unión con León en 1230 el romance siguió progresando como lengua cancilleresca ${ }^{85}$ hasta alcanzar el cien por ciento en $1252^{86}$.

\footnotetext{
${ }^{83}$ Como apunta MILLARES CARLO, A., "La cancillería real", cit. p. 267: "Desde 1204 hallamos como jefe de la cancillería a Pedro Pérez que en 1208 se titula como canonicus Sancti Jacobi. Es muy posible que sea el mismo que años adelante aparece como arcediano de Salamanca haciendo las veces de canciller (tenens vicens Cancellarii) y que más tarde - después de haber sido sustituido en sus funciones por el deán de Compostela Bernardo- volvió con el título de maestrescuela de Orense a ocupar el cargo que aún desempeñaba en el año postrero del reinado de Alfonso IX".

${ }^{84}$ MONTEAGUDO ROMERO, H. Letras primeiras. O Foral do Burgo do Caldelas, os prioratos da lírica trovadoresca e a emerxencia do galego escrito (A Coruña, 2008).

${ }^{85}$ Cfr. FERNÁNDEZ-ORDÓÑEZ, I., "La lengua de los documentos del Rey: del latín a las lenguas vernáculas en las cancillerías regias de la Península Ibérica", en La construcción medieval de la memoria regia (Madrid, 2011) p. 323-361, con actualizada bibliografía en punto al paso del latín al romance en Castilla-León.

${ }^{86}$ Hasta 1240 los documentos latinos siempre exceden a los romances. Entre 1241 y 1245 la media arroja un resultado del $45,1 \%$ de romances frente al 54, 8\% de latinos. En 1252 alcanza el 100\%. Cfr. Ibidem.
} 
La muerte en 1230 de Alfonso IX, propiciadora, como se ha dicho, de la integración definitiva de Castilla y León en la persona de Fernando II, señala el comienzo del declive de la Orden del Císter en Galicia. De él son prueba inequívoca la ausencia casi total de nuevas mercedes monárquicas y de nuevas incorporaciones de monasterios. El proceso de pérdida de notoriedad que se aprecia a medida que avanza el siglo XIII, con matices muy específicos en Galicia debido a las circunstancias especiales que acabamos de reseñar, es idéntico o similar, sin embargo, al que se detecta en otros puntos de la Península o de Europa por las mismas fechas ${ }^{87}$.

\section{BIBLIOGRAFÍA}

AELII ANTONII NEBRIGENSIS, Annotationes in Libro Pandectarum (Ael. Antonii Nebrissensis, Gramm. Opera 2). Introducción y ed. crítica por A. García, trad. por Arantxa Domingo Maldonado (Salamanca, 1996)

Álvarez ÁlVAREZ, C., "Castillos, Palacios y Torres de los Quiñones en la Baja Edad Media", en LANDERO QUESADA, M.A., (dir.) Castillos medievales del Reino de León (Madrid, 1998).

ÁLVAREZ PALENZUELA, V. A., "Iglesia y monarquía en el reinado de Fernando II", en Santo Martino de León. Ponencias del I Congreso Internacional sobre Santo Martino en el VII Centenario de su obra literaria (1185-1985), (León, 1987)

ARRIBAS ARRANZ, F., "Una importante falsificación de documentos a principios del siglo XVI", en Boletín del Museo Arqueológico Provincial de Orense, IV.

AYALA MARTÍNEZ, C., "Las órdenes militares hispánicas en la Edad Media” (siglos $X I I-X V)$ (Madrid, 2003).

BARTON, S., The aristocracy in twelfth-century León and Castille (Cambridge, 1997).

CAMPOS SÁNCHEZ BORDONA, D., Y PÉREZ GIL, J., El palacio real de León (León, 2006).

BELLO, ROMERO C., Laxe, mirando al mar (A Coruña, 1999).

${ }^{87}$ VALLE PÉREZ, J. C., "La implantación de la Orden del Cister en Galicia y su reflejo monumental durante la Edad Media", en VV. AA. en Arte del Cister en Galicia y Portugal (A Coruña, 1998) p. 8. 
CAVERO DOMÍNGUEZ, C., "Teresa de Portugal, reina de León” en Los Reyes de León (León, 1994).

CAVERO DOMÍNGUEZ, G., "Alfonso IX de León y el iter de su corte (1188-1230)" en e-Spania. Revue interdisciplinaire d'études hispaniques médiévales et modernes 8 (2009).

CAVERO DOMÍNGUEZ - GONZÁLEZ GARCÍA, M.A., El monasterio cisterciense de San Miguel de las Dueñas (León, 2000).

DE SAA BRAVO, H., El Monacato en Galicia, I (La Coruña, 1972).

DE RAZE, LAUCHAND, FLANDRIN, Concordatium SS. Scripturae Manuale (Barcelona, 1958).

DEYEMOND, A.D. Epic poetry and the clergy. Studies on the "Mocedades de Rodrigo" (Londres, 1969).

DOMÍNGUEZ SÁNCHEZ, S., Documentos pontificios referentes a la diócesis de León. Siglos XI-XIII (León, 2003).

EIROA, J.J., "Prehistoria y Antigüedad de la villa de Laxe (A Coruña)", en Varia Studia. Libro- homenaje al Prof. Dr. Luis Rodríguez Ennes, con ocasión de su septuagésimo aniversario (M. Barcia Lago y M. Fuenteseca Degeneffe (dirs.) (Pontevedra, 2015)

ESCUDERO, J.A., Curso de Historia del Derecho (Madrid, 1985).

FERNÁNDEZ CATÓN, J.M., La Curia Regia de León de 1188 y sus “decreta” y constitución (León, 1993).

FERNÁNDEZ-ORDÓÑEZ, I., "La lengua de los documentos del Rey: del latín a las lenguas vernáculas en las cancillerías regias de la Península Ibérica", en La construcción medieval de la memoria regia (Madrid, 2011).

FITA, "Biografía inédita de Alfonso IX, rey de León, por Gil de Zamora", en Boletín de la Real Academia de la Historia 13.

FREIRE CAMANIEL, J., El monacato gallego en la Alta Edad Media, II (A Coruña, 1998).

GARCÍA, C.H., "Alfonso IX de León et les cives du royaume (XII-XIII)”, en CLCHM 27 (2004).

GARCÍA GARCÍA, A., "Legislación de los Concilios y Sínodos del reino leonés" en El Reino de León en la Alta Edad Media, II, Ordenamiento Jurídico del reino (León, 1992). 
GARCÍA Y GARCÍA, A., Iglesia, Sociedad y Derecho 3 (Salamanca, 2000).

GARCÍA-OSUNA Y RODRÍGUEZ, J.M., "Historia urbana de los reinos de León y Castilla en la Alta Edad Media” en Salamanca. Revista de Estudios 57 (2008).

GONZÁLEZ, J., Alfonso IX, 2 vols. (Madrid, 1944).

GONZÁLEZ, J., Regesta de Fernando II (Madrid, 1943).

GONZÁLEZ GARCÉS, M., Alfonso IX y Crunia (A Coruña, 2008).

GONZÁLEZ VÁZQUEZ, M., El arzobispo de Santiago: una instancia de poder en la Edad Media (1150-1400) (A Coruña, 1996).

GRASSONI, H., "La ira regia en León y Castilla", en Cuadernos de Historia de España, XLI-XLII (1965).

HERNÁNDEZ VICENTE, S., "El concejo de Benavente y las tierras de su alfoz durante los siglos XII-XIV”, en ARNAU BASTEIRO, E., (Ed.) Regnum, Corona y Cortes en Benavente (1202-2002). VIII Centenario de las Cortes de Benavente (Zamora, 2002).

KRÜGER, P., Corpus Iuris Civilis, II: Codex Iustinianus (Berlín, 1887-1959).

LEWIS-SHORT, A Latin Dictionary (Oxford, 1879).

LINEHAN, P., La iglesia española y el papado en el siglo XIII (Salamanca, 1975).

LÓPEZ FERREIRO, A., Fueros municipales de Santiago y su tierra (Santiago, 18951896).

LÓPEZ FERREIRO, A., Historia de la Santa Iglesia Catedral, V (Santiago, 1902).

LÓPEZ SANGIL, J.L., La nobleza altomedieval gallega. La familia Froilaz-Traba (A Coruña, 2002).

MANSILLA, "La documentación pontificia hasta Inocencio III (965-1216)", en Monumenta Hispaniae Vaticana. Sección registros 1 (Roma, 1955).

MARTÍN, J.L., “Alfonso IX y sus relaciones con Castilla”, en Espacio, tiempo y forma, 7 (1994).

MILLARES CARLO, A., "La cancillería real en León y Castilla hasta fines del reinado de Fernando III", en AHDE 3 (1926).

MOLINA MOLINA, A.L., "Prólogo" a EIROA, J.J., El retablo de la resurrección de Santa María de la Atalaya (Laxe, A Coruña). 
MONTEAGUDO ROMERO, H., Letras primeiras. O Foral do Burgo do Caldelas, os prioratos da lírica trovadoresca e a emerxencia do galego escrito (A Coruña, 2008).

MORALEJO LASO, A., Toponimia gallega y leonesa (Santiago de Compostela, 1977).

NúÑEZ DE CASTRO, A., Crónica de los Señores Reyes de Castilla Don Sancho el Deseado, Don Alonso el Octavo y Don Enrique el Primero (Madrid, 1665).

PARGA PONDAL, S., "Viaje de Alfonso IX por tierras de Bergantiños", en Boletín de la Real Academia Gallega 27 (1956).

PARGA PONDAL, S., Comarca natural de Bergantiños (A Coruña, 2010).

PASCUAL MADOZ, Diccionario Geográfico-Estadístico-Histórico de España y sus posesiones de Ultramar (Madrid, 1845), T. VI, Galicia.

PISKORSKI, W., Las Cortes de Castilla en el período de tránsito de la Edad Media a la Moderna, reedic. (Barcelona, 1977).

PORRINAS GONZÁLEZ, D., "Alfonso IX y la desconocida conquista de Badajoz en 1230", en Sharia 71 (Badajoz, 2012).

RECUERO ASTRAY, M., "Alfonso IX, rey de León y de Galicia (1188-1230), repoblador de A Coruña (1208)", en Alfonso IX de León y su época (A Coruña, 2008).

RECUERO ASTRAY, M., "Relaciones entre la monarquía y la Iglesia de León durante la Alta Edad Media", en El reino de León en la Alta Edad Media, VII (León, 1995).

RODRÍGUEZ CASAL, A., "Carta arqueológica del partido judicial de Carballo de Bergantiños (La Coruña)” Studia Arqueologica 34 (Santiago, 1975).

RODRÍGUEZ ENNES, L., Aproximación a la Historia Jurídica de Galicia (Santiago de Compostela, 1999).

RODRÍGUEZ ENNES, L., Las divisiones provinciales de Galicia: pasado, presente y futuro (Vigo, 2002).

RODRÍGUEZ FIGUEIREDO, M., “Alfonso IX en Pontevedra”, en Museo de Pontevedra XXIX (1975).

SALAZAR ACHA, J., La Casa del Rey de Castilla y León en la Edad Media (Madrid, 2000).

SALVADO MARTÍNEZ, A., Tumbo de Toxosoutos. Siglos XII y XIII, doc. 6 (22-II1146); doc. 14 (2-XII-1154); doc. 56 (7-IV-1283) y doc. 21 (13-1-1169),

TORRES SEVILLA-QUIÑONES DE LEÓN, M., Linajes nobiliarios de León y Castilla. Siglos IX-XII (León, 1990). 
VAAMONDE LORES, C., "Santa Marina de Gomariz", en Boletín de la Comisión de Monumentos de Orense (en lo sucesivo BCMO), IV, 1910-1913.

VALLE PÉREZ, J. C. La arquitectura cirterciense en Galicia I (A Coruña, 1982).

VALLE PÉREZ, J. C., "La implantación de la Orden del Cister en Galicia y su reflejo monumental durante la Edad Media", en VV. AA. en Arte del Cister en Galicia y Portugal (A Coruña, 1998).

VATASSO, M., Initia patrum latinorum aliorumque scriptorum eccleriasticorum latinorum ex Migne Patrologia et ex compluribus aliis libris (Ciudad del Vaticano, 1906) (Studi e Testi 16).

VIDAL PÉREZ, X., Catalogación toponímica de Concello de Laxe (Laxe, s. f.)

VILLA-AMIL Y CASTRO, J., Los pertigueros de la Iglesia de Santiago (Madrid, 1873).

VILLA-AMIL Y CASTRO, J., "Rodrigo Gómez: cuadro histórico de las costumbres de la nobleza gallega en el siglo XII”, en Grial 33 (1971)

YAÑEZ NEIRA, D., Monasticon Cirterciense Gallego II (León, 2000).

YEPES, Fray A. de, Crónica General de la Orden de San Benito, III (1609-1621). 